\title{
Evaluation of a deworming campaign by albendazole during 2016 in a rural area of Giza Governorate, Egypt
}

\section{Original Article}

\author{
Salwa MA Dahesh
}

Malaria and Filaria Training Center, General Administration of Endemic Diseases Control of Giza, Ministry of Health and Population, Research Institute of Medical Entomology, The General Organization for Institutes and Teaching Hospitals, Ministry of Health and Population, Egypt

\begin{abstract}
Background: Egypt carried out the first national deworming campaign in 2016 targeting two million school-age children. The control program was led by the Endemic Diseases Department of the Egyptian Ministry of Health and Population (MOHP), in collaboration with the WHO Office in Egypt. Endemic Diseases Control Administration of Giza Governorate selected Tamwah village for the present work to represent the rural areas of Giza Governorate. The campaign targeted children from the first grade of primary schools aging around six years. In that campaign the children were treated with two doses of albendazole tablets $400 \mathrm{mg}$ (two weeks apart).

Objective: The present work aimed to evaluate the deworming campaign conducted during 2016 in one of the rural areas of Giza Governorate, Egypt and the efficacy of albendazole, the chosen treatment, in reducing parasitic infection rates among the targeted age group. The intention was to upgrade the results of the campaign by examining the same targeted group of children post treatment in comparison with a control group of untreated children from the same area thus widening the range of selected children. Also to collect environmental and epidemiological data for the study area of the examined children for constructing a new coordinative collaborative program suitable for controlling not only the soil transmitted parasites but also other endemic disease as schistosomiasis found in our study area.

Subjects and methods: This cross-sectional study targeted two groups. The first group included all children of grade one in three primary schools who had received two doses of $400 \mathrm{mg}$ albendazole tablets, two weeks apart. The second group (control group) included children of grade two who had not received medication. Stool specimens and anal swabs were collected from both treated and untreated control groups two weeks after receiving the second dose of treatment for the treated group. Personal and environmental data were recorded. The stool samples were examined by direct wet smear and kato-katz technique. The anal swabs were examined by saline swab method recommended for detection of Enterobius vermicularis ova. The data were tabulated and statistically analyzed.

Results: E. vermicularis was the most prevalent parasite among the untreated group followed by E. histolytica/dispar, G. intestinalis and H. nana. Parasite rate of E. vermicularis among untreated females was twice that among males. The difference was statistically significant. Mass treatment with albendazole, resulted in significant differences between the parasite rates among the untreated and treated groups regarding E. vermicularis, E. histolytica/dispar and G. intestinalis. Treatment had no effect on parasite rate of H. nana. Generally the infection rates whether single or mixed, were significantly higher among untreated children than treated ones.

Conclusion: The strategy of selecting albendazole for mass treatment in such areas proved appropriate, and suitably chosen since most of the prevalent parasites encountered were greatly affected. As Tamwah village was assessed previously as a low endemic area of urinary schistosomiasis, coordination between both soil transmitted helminthes (STHs) and schistosomiasis control programs $(\mathrm{SCH})$ should be conducted for organizing and saving efforts, trained manpower and transportation. Mass treatment should not be restricted to children of grade one but should include children of all grades in the primary schools (enrolled and non-enrolled) for further reduction of helminthic transmission.
\end{abstract}

Key Words: Albendazole, deworming, Egypt, mass drug administration, soil transmitted helminthes, STHs, Tamwah.

Received: 21 August 2017, Accepted: 25 December, 2017.

Corresponding Author: Salwa MA Dahesh, Tel. : +20-10-1678-7766, E-mail: salwamohamed970@gmail.com.

ISSN: 1687-7942, Vol. 11, No. 1, April 2018.

\section{INTRODUCTION}

The terms geohelminthes or STHs refer to parasites whose life cycles require a period outside the human host in warm moist soil. Hence their mode of infection is mostly through contact with contaminated soil containing eggs or larvae of the parasites ${ }^{[1]}$. According to their life cycles and modes of infection STHs can be divided into three groups; the first group includes parasites that can be transmitted directly by autoinfection as E. vermicularis since the eggs 
do not require a period of maturation to become infective. The second group includes those of modified direct transmission whose eggs require a period in suitable soil to be infective before ingestion as $A$. lumbricoides, $T$. trichiura and Toxocara spp. In the third group the eggs are laid in soil, hatch and the larvae undergo further development before being able to penetrate the skin as in A. duodenale, $N$. americanus and $S$. stercoralis. S. stecoralis differs from members of this group since its larvae can betransmitted by autoinfection and also can complete a free living life cycle in soil without need for a human host ${ }^{[2]}$.

Several protocols of chemotherapy mass treatment programs were established by the Global Network for Neglected Tropical Diseases (NTDs) for controlling STHs in affected communities. The programs focused on three targeted groups; school aged children, preschool children and pregnant women ${ }^{[3-5]}$. Five safe broad-spectrum de-worming drugs were recommended in large scale programs; mebendazole, albendazole, ivermectin, pyrantel and levamisole. After planning and implementing control activities, monitoring and evaluation were carried out to ensure efficient implementation and maximal benefits for infected individuals, their families and communities ${ }^{[5,6]}$.

A control program was led by the Endemic Diseases Department of the Egyptian Ministry of Health and Population (MOHP), in collaboration with the WHO Office in Egypt targeting two million school-age children. The targeted children were those in the first grade of primary schools aging around six years. The children were asked to take two doses of albendazole $400 \mathrm{mg}$ (two weeks apart between the first and the second doses). The campaign started on March $13^{\text {th }}$ and lasted up to April $7^{\text {th }}$, 2016 covering 1980708 school children in 271 districts of twenty seven Governorates ${ }^{[7]}$. The present work started two weeks after completion of the second dose of albendazole treatment implemented in this national deworming campaign. For evaluation of the efficacy of albendazole in reducing parasitic infection rates among the targeted age group,Tamwah village which was included in the campaign of mass treatment, was chosen as an example for post campaign evaluation by stool and anal swab analysis examinations after the campaign task was over. Also it was essential to collect environmental and epidemiological data for the study area of the examined children. Relevant data may be used for constructing a new coordinative collaborative program suitable for controlling not only the soil transmitted parasites but also other endemic disease as schistosomiasis found in our study area.

\section{SUBJECTS AND METHODS}

Study area: For the present work, the Endemic Diseases Control Administration of Giza Governorate selected Tamwah village that was part of the original campaign, to represent the rural areas of Giza Governorate because of its bad environmental condition, lack of sanitation, low quality of tap water inside houses, high prevalence of enterobiasis and urinary schistosomiasis ${ }^{[8]}$. Tamwah village belongs to Abu Alnomros District, Giza Governorate. The borders of Tamwah village are Manyal Shihah at North, Albadrashin District at South, Met Shamasi at West, and the River Nile at East. The location by Global positioning system (GPS) was 29.939720, 31.265508. Its consensus was about 28,000 during 2016. There are three primary schools in the village; Osman ben Affan, Fatma Alzahraa and Tamwah primary schools.

Parasitological survey: Mass treatment implemented with the first dose of albendazole $400 \mathrm{mg}$ for only children of grade one was completed by $15^{\text {th }}$ of March 2016 . Medication with the second dose was completed on $30^{\text {th }}$ of March (two weeks apart from the first dose) in the three schools of Tamwah village. The present practical field work started after two weeks from the second dose on $14^{\text {th }}$ of April 2016. The cross-sectional study targeted two groups; the first group included all children of grade one from the three primary schools, administered a single dose of albendazole tablets; the second group (control group) included children of grade two who did not receive medication. Each child of both groups received a $30 \mathrm{ml}$ sterile capped container for stool sample and a sterile saline swab in a tightly closed tube; with a paper containing instructions for mothers of children tutoring them on how, when and who should help the child in obtaining the swab first thing in the morning before bathing. The instruction paper was provided also with mobile number of the researcher for more explanation. A total of 1740 stool samples, 859 samples from children of grade one and 881 from grade two were collected and labeled. Also a total of 653 anal swabs, 288 swabs from children of grade one and 365 swabs from grade two were collected and labeled in the medical laboratory of Tamwah Health Unit. A new questionnaire concerning children of group one and environmental data, were recorded. The data and mobile number of each child's family were collected from the child and his/her family. The stool specimens were examined by direct wet smear and kato-katz technique and the anal swabs by saline swab method recommended for detection of $E$. vermicularis ova ${ }^{[9]}$. Reports of results were prepared and given to the parents to receive their free medication (if needed) from the Tamwah Health Unit. Prior to starting of the study and until the end, the researcher, managers and teachers of the schools educated the children and their parents on how to avoid infections with helminthes particularly those transmitted by autoinfection.

Statistical analysis: The personal and environmental data together with the results of stool samples and anal swabs were entered into PC for statistical analysis using SPSS version 20 (IBM, Inc. New York, USA). Tests of non-parametric analysis as Chi-square test, likelihood and Exact tests were chosen to compare differences between different parasite rates among untreated and treated groups. Children who did not receive the two doses of albendazole 
in grade one were excluded. The 0.05 cut-off value was selected as a criterion for significance ${ }^{[10,11]}$.

Ethical consideration: The study was carried out under supervision of the MOHP. All examined persons were health educated and agreed to contribute before sampling. Mothers were instructed on how to perform the anal swabs for their children.

\section{RESULTS}

Parasitological survey: The distribution of the examined children according to their gender and primary grade was statistically insignificant $(P>0.05)$. The control group (untreated group) was chosen from the same schools of the treated group but from grade two, the nearest age group to grade one (Table 1). The children of grade one who did not receive the two doses were excluded from the study and referred to health workers for their doses. Concerning the parasite rate among the untreated group, E. vermicularis was the most prevalent parasite rating $20.3 \%$ (74 positive cases out of 365 examined anal swabs) where $653(37.5 \%)$ out of 1740 examined children provided their anal swab samples (Table1). The prevalence of enterobiasis among untreated female children (31.9\%) was twice that of untreated male children $(14.6 \%)$. The difference was statistically significant $(P<0.05)$ (Table 3 ). All anal swabs of treated children were negative for eggs or adults of $E$. vermicularis. The difference between treated and untreated groups was statistically significant $(P<0.05)$ among both genders (Tables 2 and 3 ).

The second prevalent parasite among the untreated children was E. histolytica/dispar. Total of positive cases was $153(17.3 \%$ ) (Table 2); 77 (8.7\%) had single infection,
$74(8.4 \%)$ had mixed infection with $G$. intestinalis and $2(0.2 \%)$ with $H$. nana (Table 4$)$. The third prevalent parasite detected among the untreated children was G. intestinalis (16\% in 141 cases); $7.6 \%$ were infected with $G$. intestinalis only and $8.4 \%$ had mixed infection with E. histolytica/dispar (Tables 2 and 4). No statistical significant differences were found between infection rates between the two genders. The results recorded statistically significant differences between untreated and treated children with albendazole $(17.3 \%, 11.8 \%$ respectively) for E. histolytica/dispar, and $(16 \%, 4.7 \%$ respectively) for G. intestinalis (Tables 2 and 4).

H. nana was the only cestode parasite detected in the studied group recording the lowest prevalence among other intestinal parasites (Table 2). Among the untreated group eleven cases $(1.2 \%)$ were positive for $H$. nana; nine of them had single infection and two cases had mixed infection with E. histolytica/dispar. No statistical difference was found between infection rates of $H$. nana among the genders. Albendazole had no effect on infection with $H$. nana where there was no statistical difference between infection rates of $H$. nana among untreated $(1.2 \%)$ and treated group $(1.4 \%)$ (Tables 2 and 4). Both single and mixed infections were decreased significantly among the treated group, while the number of children free from parasites was significantly higher in untreated group (Table 4, Figure $1)$. Generally the infection rates whether single or mixed (21.5\% and $8.6 \%$ respectively) were significantly higher among untreated individuals than treated ones $(11.8 \%$ and $3.1 \%$ respectively) (Table 4 ). There was no statistical difference between parasitic infection among untreated males and females, meanwhile among albendazole-treated children the rate of $E$. histolytica/dispar among males was significantly lower than that among females (Table5).

Table 1: Distribution of the examined children according to their gender and primary grade.

\begin{tabular}{|c|c|c|c|c|c|}
\hline & & \multicolumn{2}{|c|}{ Primary grade } & \multirow[b]{2}{*}{ Total } & \multirow[b]{2}{*}{$\begin{array}{c}\text { Statistical } \\
\text { Analysis }\end{array}$} \\
\hline \multicolumn{2}{|c|}{$\operatorname{Sex}$} & $\begin{array}{l}\text { Grade one } \\
\text { (Treated) }\end{array}$ & $\begin{array}{c}\text { Grade two } \\
\text { (Untreated) }\end{array}$ & & \\
\hline \multirow{2}{*}{ Male } & No. & 426 & 437 & 863 & \multirow{4}{*}{$\begin{array}{c}\text { Pearson Chi } \\
\text { square }=0.079 \\
P>0.05\end{array}$} \\
\hline & $\%$ & $49.4 \%$ & $50.6 \%$ & $100.0 \%$ & \\
\hline \multirow[b]{2}{*}{ Female } & No. & 427 & 450 & 877 & \\
\hline & $\%$ & $48.7 \%$ & $51.3 \%$ & $100.0 \%$ & \\
\hline \multirow[b]{2}{*}{ Total } & No. & 853 & 887 & 1740 & \\
\hline & $\%$ & $49.0 \%$ & $51.0 \%$ & $100.0 \%$ & \\
\hline
\end{tabular}


Evaluation of a deworming campaign in Giza Dahesh

Table 2: Prevalence of parasitic infections in albendazole treated and untreated regardless of being single or mixed infection.

\begin{tabular}{|c|c|c|c|c|}
\hline \multirow{2}{*}{$\begin{array}{l}\text { Results of stool } \\
\text { examination }\end{array}$} & & \multicolumn{2}{|c|}{ Albendazole } & \multirow{2}{*}{$\begin{array}{l}\text { Statistical analysis } \\
\text { Fisher's Exact Test }\end{array}$} \\
\hline & & Treated & Untreated & \\
\hline \multirow[t]{2}{*}{ Positive } & No. & $127 \mathrm{a}$ & $273_{\mathrm{b}}$ & \multirow[t]{2}{*}{$P<0.05$} \\
\hline & $\%$ & $14.9 \%$ & $30.1 \%$ & \\
\hline \multirow[t]{2}{*}{ Negative } & No. & $726_{a}$ & $620_{b}$ & \multirow[t]{2}{*}{$P<0.05$} \\
\hline & $\%$ & $85.1 \%$ & $69.9 \%$ & \\
\hline \multirow{2}{*}{$\begin{array}{l}\text { E. histolytica/ } \\
\text { dispar }\end{array}$} & No. & $77_{a}$ & $153_{\mathrm{b}}$ & \multirow{2}{*}{$P<0.05$} \\
\hline & $\%$ & $9.0 \%$ & $17.2 \%$ & \\
\hline \multirow{2}{*}{ E. coli } & No. & $25 \mathrm{a}$ & $38_{\mathrm{b}}$ & \multirow{2}{*}{$P<0.05$} \\
\hline & $\%$ & $2.9 \%$ & $4.2 \%$ & \\
\hline \multirow{2}{*}{ G. intestinalis } & No. & $40_{\mathrm{a}}$ & $141_{\mathrm{b}}$ & \multirow{2}{*}{$P<0.05$} \\
\hline & $\%$ & $4.7 \%$ & $16 \%$ & \\
\hline \multirow{2}{*}{ E. vermicularis } & No. & $0_{a}$ & $74_{b}$ & \multirow{2}{*}{$P<0.05$} \\
\hline & $\%$ & $0.0 \%$ & $20.3 \%$ & \\
\hline \multirow{2}{*}{ H. nana } & No. & $12_{\mathrm{a}}$ & $11_{\mathrm{a}}$ & \multirow{2}{*}{$P<0.05$} \\
\hline & $\%$ & $1.4 \%$ & $1.2 \%$ & \\
\hline \multirow{2}{*}{ Total } & No. & 853 & 887 & \multirow{2}{*}{$\begin{array}{c}\text { Pearson Chi- } \\
\text { Square }=82.7, P<0.05\end{array}$} \\
\hline & $\%$ & $100.0 \%$ & $100.0 \%$ & \\
\hline
\end{tabular}

Subscript letter (a) differs significantly from letter (b) inside the same row at the 0.05 level.

Table 3: Distribution of E. vermicularis among genders in albendazole treated and untreated children.

\begin{tabular}{|c|c|c|c|c|c|c|}
\hline \multirow{2}{*}{\multicolumn{3}{|c|}{ Gender and Enterobiasis* }} & \multicolumn{2}{|c|}{ Treatment with albendazole } & \multirow{2}{*}{ Total } & \multirow{2}{*}{ Statistical analysis } \\
\hline & & & Treated & Untreated & & \\
\hline \multirow{6}{*}{ Male } & \multirow{2}{*}{ Positive } & No. & $0_{\mathrm{a}}$ & $36_{b}$ & 36 & \multirow{6}{*}{$\begin{array}{l}\text { Likelihood Ratio= } \\
26.310, P<0.05 \\
\text { Fisher's Exact Test, } \\
P<0.05\end{array}$} \\
\hline & & $\%$ & $0.0 \%$ & $14.6 \% * *$ & $8.8 \%$ & \\
\hline & Negative & No. & $164_{a}$ & $210_{b}$ & 374 & \\
\hline & & $\%$ & $100.0 \%$ & $85.4 \%$ & $91.2 \%$ & \\
\hline & \multirow{2}{*}{ Total } & No. & 164 & 246 & 410 & \\
\hline & & $\%$ & $100.0 \%$ & $100.0 \%$ & $100.0 \%$ & \\
\hline \multirow{6}{*}{ Females } & \multirow{2}{*}{ Positive } & No. & $0_{\mathrm{a}}$ & $38_{b}$ & 38 & \multirow{6}{*}{$\begin{array}{l}\text { Likelihood Ratio= } \\
46.937, P<0.05 \\
\text { Fisher's Exact Test, } \\
P<0.05\end{array}$} \\
\hline & & $\%$ & $0.0 \%$ & $31.9 \% * *$ & $15.6 \%$ & \\
\hline & Negative & No. & $124_{\mathrm{a}}$ & $81 b$ & 205 & \\
\hline & Negative & $\%$ & $100.0 \%$ & $68.1 \%$ & $84.4 \%$ & \\
\hline & \multirow{2}{*}{ Total } & No. & 124 & 119 & 243 & \\
\hline & & $\%$ & $100.0 \%$ & $100.0 \%$ & $100.0 \%$ & \\
\hline \multirow{6}{*}{ Total } & \multirow{2}{*}{ Positive } & No. & $0_{\mathrm{a}}$ & $74_{b}$ & 74 & \multirow{6}{*}{$\begin{array}{l}\text { Likelihood Ratio= } \\
65.852, P<0.05 \\
\text { Fisher's Exact Test, } \\
P<0.05\end{array}$} \\
\hline & & $\%$ & $0.0 \%$ & $20.3 \%$ & $11.3 \%$ & \\
\hline & Negative & No. & $288_{\mathrm{a}}$ & $291_{b}$ & 579 & \\
\hline & Negative & $\%$ & $100.0 \%$ & $79.7 \%$ & $88.7 \%$ & \\
\hline & \multirow{2}{*}{ Total } & No. & 288 & 365 & 653 & \\
\hline & & $\%$ & $100.0 \%$ & $100.0 \%$ & $100.0 \%$ & \\
\hline
\end{tabular}

*By saline anal swab method

**Fisher's Exact test (difference between males and females untreated children was significant), $P<0.05$.

Subscript letter (a) differs significantly from letter (b) inside the same row at the 0.05 level. 
PARASITOLOGISTS UNITED JOURNAL

Table 4: Prevalence of parasitic infection in albendazole-treated and untreated groups.

\begin{tabular}{|c|c|c|c|c|c|c|}
\hline & \multirow{2}{*}{\multicolumn{2}{|c|}{ Results of stool examination }} & & \multicolumn{2}{|c|}{ Albendazole } & \multirow{2}{*}{$\begin{array}{l}\text { Statistical analysis } \\
\text { Fisher's Exact Test }\end{array}$} \\
\hline & & & & Treated & Untreated & \\
\hline Negative & & & $\begin{array}{c}\text { No. } \\
\%\end{array}$ & $\begin{array}{c}726_{\mathrm{a}} \\
85.1 \%\end{array}$ & $\begin{array}{c}620_{b} \\
69.9 \%\end{array}$ & $P<0.05$ \\
\hline \multirow{10}{*}{ Positive } & \multirow{5}{*}{$\begin{array}{c}\text { Single } \\
\text { infection }\end{array}$} & $\begin{array}{l}\text { E. histolytica/ } \\
\text { dispar }\end{array}$ & $\begin{array}{l}\text { No. } \\
\%\end{array}$ & $\begin{array}{c}50 \\
\text { a } \\
5.9 \%\end{array}$ & $\begin{array}{c}77_{\mathrm{b}} \\
8.7 \%\end{array}$ & $P<0.05$ \\
\hline & & E. coli & $\begin{array}{l}\text { No. } \\
\%\end{array}$ & $\begin{array}{c}25 \mathrm{a} \\
2.9 \%\end{array}$ & $\begin{array}{c}38 \mathrm{~b} \\
4.2 \%\end{array}$ & $P<0.05$ \\
\hline & & H. nana & $\begin{array}{c}\text { No. } \\
\%\end{array}$ & $\begin{array}{c}3 \mathrm{a} \\
0.4 \%\end{array}$ & $\begin{array}{c}9 \\
\mathrm{a} \\
1.0 \%\end{array}$ & $P<0.05$ \\
\hline & & G. lamblia & $\begin{array}{c}\text { No. } \\
\%\end{array}$ & $\begin{array}{c}22_{\mathrm{a}} \\
2.6 \%\end{array}$ & $\begin{array}{c}67 \mathrm{~b} \\
7.6 \%\end{array}$ & $P<0.05$ \\
\hline & & Total & $\begin{array}{c}\text { No. } \\
\%\end{array}$ & $\begin{array}{c}100 \mathrm{a} \\
11.8 \%\end{array}$ & $\begin{array}{c}191_{\mathrm{b}} \\
21.5 \%\end{array}$ & $P<0.05$ \\
\hline & \multirow{3}{*}{$\begin{array}{c}\text { Mixed } \\
\text { infection }\end{array}$} & $\begin{array}{l}\text { E. histolytica \& } \\
\text { G. lamblia }\end{array}$ & $\begin{array}{c}\text { No. } \\
\%\end{array}$ & $\begin{array}{c}18 \mathrm{a} \\
2.1 \%\end{array}$ & $\begin{array}{c}74 \mathrm{~b} \\
8.3 \%\end{array}$ & $P<0.05$ \\
\hline & & $\begin{array}{l}\text { E. histolytica \& } \\
\text { H. nana }\end{array}$ & $\begin{array}{l}\text { No. } \\
\%\end{array}$ & $\begin{array}{c}9 \\
\mathrm{a} \\
1.0 \%\end{array}$ & $\begin{array}{c}2 \mathrm{~b} \\
0.2 \%\end{array}$ & $P<0.05$ \\
\hline & & Total & $\begin{array}{c}\text { No. } \\
\%\end{array}$ & $\begin{array}{r}27 \mathrm{a} \\
3.1 \% \\
\end{array}$ & $\begin{array}{r}76_{\mathrm{b}} \\
8.6 \% \\
\end{array}$ & $P<0.05$ \\
\hline & \multicolumn{2}{|l|}{ Total } & $\begin{array}{c}\text { No. } \\
\%\end{array}$ & $\begin{array}{c}127 \mathrm{a} \\
14.9 \%\end{array}$ & $\begin{array}{c}273^{\mathrm{b}} \\
30.1 \%\end{array}$ & $P<0.05$ \\
\hline & \multicolumn{2}{|c|}{ Total } & $\begin{array}{c}\text { No. } \\
\%\end{array}$ & $\begin{array}{c}127 \mathrm{a} \\
14.9 \%\end{array}$ & $\begin{array}{c}273_{\mathrm{b}} \\
30.1 \%\end{array}$ & $P<0.05$ \\
\hline
\end{tabular}

Subscript letter (a) differs significantly from letter (b) inside the same row at the 0.05 level.

Table 5: Rates of parasitic infection among males and females, in albendazole-treated and untreated children.

\begin{tabular}{|c|c|c|c|c|c|c|}
\hline \multirow{2}{*}{$\begin{array}{l}\text { Results of stool } \\
\text { examination }\end{array}$} & & \multicolumn{2}{|c|}{ Treated } & \multicolumn{2}{|c|}{ Untreated } & \multirow{2}{*}{$\begin{array}{c}\text { Statistical } \\
\text { analysis }\end{array}$} \\
\hline & & Male & Female & Male & Female & \\
\hline \multirow{2}{*}{ Negative } & No. & $373_{\mathrm{a}}$ & $353_{b}$ & $298_{a}$ & $322 \mathrm{a}$ & \multirow{16}{*}{$\begin{array}{c}\text { Untreated group } \\
\text { Pearson Chi- } \\
\text { Square }=4.882, \\
P>0.05 \\
\text { Likelihood } \\
\text { Ratio }=5.662, \\
P>0.05 \\
\text { Treated group } \\
\text { Pearson Chi- } \\
\text { Square }=7.514,\end{array}$} \\
\hline & $\%$ & $* * 87.6 \%$ & $* * 82.7 \%$ & $68.2 \%$ & $71.6 \%$ & \\
\hline \multirow{2}{*}{$\begin{array}{l}\text { E. histolytica/ } \\
\text { dispar }\end{array}$} & No. & 20 & $30_{b}$ & $39 \mathrm{a}$ & $38 \mathrm{a}$ & \\
\hline & $\%$ & $4.6 \% * *$ & $7 \% * *$ & $8.9 \%$ & $8.5 \%$ & \\
\hline \multirow{2}{*}{ E. coli } & No. & 9 & 16 & 19 a & 19 a & \\
\hline & $\%$ & $2.2 \%$ & $3.8 \%$ & $4.3 \%$ & $4.2 \%$ & \\
\hline \multirow{2}{*}{ G. intestinalis } & No. & $11_{\mathrm{a}}$ & $11_{\mathrm{a}}$ & $39 \mathrm{a}$ & $28_{\mathrm{a}}$ & \\
\hline & $\%$ & $2.6 \%$ & $2.6 \%$ & $8.9 \%$ & $6.2 \%$ & \\
\hline \multirow{2}{*}{$\begin{array}{l}\text { E. histolytica \& } \\
\text { G. intestinalis }\end{array}$} & No. & $6.2 \%$ & $9_{\mathrm{a}}$ & $35_{\mathrm{a}}$ & $39 \mathrm{a}$ & \\
\hline & $\%$ & $2.1 \%$ & $2.1 \%$ & $8.0 \%$ & $8.7 \%$ & \\
\hline \multirow{2}{*}{ H. nana } & No. & $0_{\mathrm{a}}$ & $3_{\mathrm{a}}$ & $5_{a}$ & $4_{a}$ & \\
\hline & $\%$ & $0.0 \%$ & $0.7 \%$ & $1.1 \%$ & $0.9 \%$ & \\
\hline \multirow{2}{*}{$\begin{array}{l}\text { E. histolytica \& } \\
\text { H. nana }\end{array}$} & No. & $4_{\mathrm{a}}$ & $5_{\mathrm{a}}$ & $2_{\mathrm{a}}$ & $0_{\mathrm{a}}$ & \\
\hline & $\%$ & $0.9 \%$ & $1.2 \%$ & $0.5 \%$ & $0.0 \%$ & \\
\hline \multirow{4}{*}{ Total } & No. & 426 & 427 & 437 & 450 & \\
\hline & $\%$ & $100.0 \%$ & $100.0 \%$ & $100.0 \%$ & $100.0 \%$ & \\
\hline & & \multicolumn{2}{|c|}{$* * P<0.05$} & \multicolumn{2}{|c|}{$P>0.05$} & \\
\hline & & \multicolumn{2}{|c|}{$\begin{array}{l}\text { Significant difference between } \\
\text { males and females }\end{array}$} & \multicolumn{2}{|c|}{$\begin{array}{c}\text { No significant difference } \\
\text { between males and females }\end{array}$} & \\
\hline
\end{tabular}




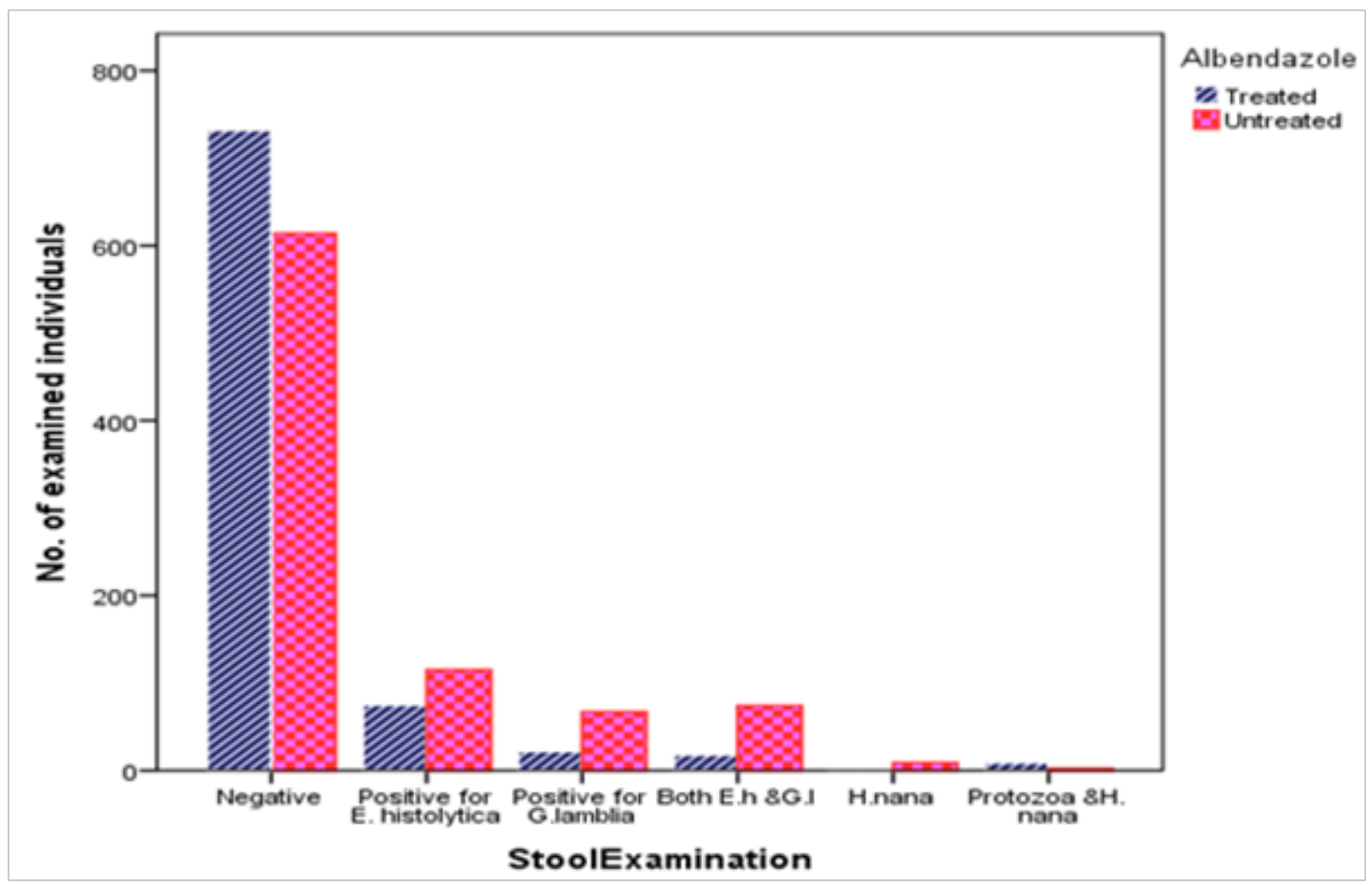

Fig. 1: Prevalence of parasitic infection among albendazole-treated and untreated groups".

\section{DISCUSSION}

Egypt is one of the countries that adopted the recent global strategy to eliminate parasitic infections particularly STHs and Schistosoma spp. Albendazole was chosen for this control program as it is a safe heat-stable drug that is easily administered, besides being recommended for de-worming mass treatment by WHO. The campaign had targeted grade one from each primary school because of their low immunity and high infection rates. The Ministry of Health and WHO collaborated with the Ministry of Education for providing a good infrastructure platform. School teachers helped in achieving the mission covering 1980708 out of two million targeted school children $(99.03 \%)^{[7]}$. All grade one in primary schools of both urban and rural areas were included in that campaign. The number of children targeted in rural areas of Giza governorate; was 97911. Out of this number; 95672 (97.7\%) received treatment. Abu Alnomros District which is one of the rural areas of Giza Governorate included 8701 targeted children; and 8266 children $(95 \%)$ received the treatment (information was kindly provided by General Administration of Endemic Diseases Control of Giza Governorate). The control untreated group was chosen from the same schools of the treated group and from grade two, the nearest age group to grade one. Distribution of examined individuals according to their gender and primary grade was homogenous with no statistically significant difference between numbers of examined boys or girls in grade one and grade two.
Concerning the parasite rate among the untreated group, it was found that $E$. vermicularis was the most common parasite with a prevalence of $20.3 \%$ ( 74 positive cases out of 365 examined anal swabs). All in all, only 653 (37.5\%) out of 1740 examined children brought their anal swab samples. The prevalence of entrobiasis among untreated female children was $(31.9 \%)$, twice that of untreated male children (14.6\%). The difference was statistically significant. The results agreed with Bahager et al. who in 1995 reported the prevalence rates of entrobiasis among female and male children aged 6-12 years as $40 \%$ and $34 \%$ respectively in Alkatta village, Giza Governorate ${ }^{[12]}$. In a urinary schistosomiasis survey carried out in Tamwah village, the same area of the present work, targeting all ages of primary children during 2016; E. vermicularis ova were accidentally detected in the urine samples of $0.54 \%$ where all positive cases were females in/under grade three ${ }^{[8]}$. Probably these ova were accidently found in urine samples of females as a result of contamination from the perianal area during sampling. Studies reported that stool examination without applying perianal anal swab methods, detected only about $5-15 \%$ of infection with E. vermicularis so Scotch tape, cellophane-tape or saline swab methods are recommended for detection of this parasite $^{[2,9]}$. Generally E. vermicularis is worldwide distributed, being more prevalent among children than adults. Its prevalence and transmission increase under crowded conditions as in schools or institutions where it can be transmitted via various methods; external autoinfection, 
retro-infection, ingestion or even inhalation of the light characteristic eggs of the parasite ${ }^{[2,13-15]}$.

Concerning the effect of mass treatment with albendazole on entrobiasis, it was found that all anal swabs of the treated children were negative for eggs or adults of E. vermicularis. The difference between treated and untreated groups was statistically significant. The results agreed with studies describing albendazole as the drug of choice for treating entrobiasis ${ }^{[2]}$. Because albendazole is a safe heat-stable drug, that does not require cooling for preservation during distribution it is recommended for treatment of helminthes in children ${ }^{[6,7]}$.

The second prevalent parasite among the untreated children was $E$. histolytica/E. dispar. Total of positive cases was $153(17.3 \%) ; 77(8.7 \%)$ of them had single infection, $74(8.4 \%)$ had mixed infection with $G$. intestinalis, and $2(0.2 \%)$ with $H$. nana. The prevalence of $G$. intestinalis the third parasite detected among the untreated children, was $16 \%$ (141 cases); $7.6 \%$ were infected with $G$. intestinalis only, and $8.4 \%$ had mixed infection with E. histolytical dispar. No statistical significant differences were found between infection rates among the two genders. Similar prevalences of $18 \%$ for E. histolytica/dispar, and $16.4 \%$ for $G$. intestinalis were recorded among school age children, while the prevalence of protozoa infection among females was higher than that in males ${ }^{[16,17]}$. Another study found that the prevalence of giardiasis among male children was higher than that of females ${ }^{[18]}$, but Parado et al ${ }^{[19]}$ agreed with results of the present work regarding the absence of difference between the two genders.

Regarding the effect of mass treatment with two doses of albendazole, the results of the present study recorded statistically significant differences between untreated and treated children with albendazole. Results were $17.3 \%$ and $11.8 \%$ respectively for $E$. histolytica/ dispar, and $16 \%$ and $4.7 \%$ respectively for $G$. intestinalis between treated and untreated groups of chilren. Although albendazole is not the treatment of choice for either amoebiasis or giardiasis, the albendazole campaign showed a marked reduction of amoebiasis and giardiasis among the treated children. The results of the present work agreed with Speich et al. ${ }^{[17]}$ who studied the effect of different drugs on protozoa. They recorded $60 \%$ and $57 \%$ cure rates due to treatment with a single dose of albendazole for infections with E. histolytica/dispar and G. intestinalis respectively. Generally the recommended treatment for protozoa is by compounds as metronidazole, ornidazole and tinidzole ${ }^{[20]}$. Also multiple doses of albendazole or nitazoxanide can be used as alternative effective agent against intestinal protozoa $^{[21-23]}$.

Hymenolepis nana was the only cestode parasite detected in the study groups. It showed the lowest rate among the recorded results. Among the untreated group eleven cases $(1.2 \%)$ were positive for $H$. nana; nine of them had single parasitic infection while the remaining two cases had mixed infection with $E$. histolytica/dispar. No statistical difference was found between infection rates of $H$. nana among the two genders. The parasite is very common particularly among children where it can be transmitted by autoinfection through fecal oral $\operatorname{transmission}^{[24]}$.

Albendazole had no effect on infection with $H$. nana where there was no statistical difference found between infection rates of $H$. nana among untreated $(1.2 \%)$ and treated groups $(1.3 \%)$. The drug of choice for treatment of $H$. nana is a single dose of praziquantel with a minimum of $20 \mathrm{mg} / \mathrm{kg}$. Niclosamide is also recommended ${ }^{[24]}$.

Geohelminths as A. lumbricoide, $A$. duodenales, T. trichura and $S$. stercoralis were not detected in the examined stool samples of grade one or grade two children. This result may reflect the good behavior of children by not defecating outdoors, where eggs of these parasites require a period of time in humid soil to be the infective $\mathrm{e}^{[1]}$

The environmental condition of the schools in the study area was bad where tap water inside the school was not continuously available and was replaced by covered and uncovered tanks full of stored water in the bathrooms. The methods followed by little children during cleaning themselves after defecation using the same container by their polluted hands spread the infective stages as cysts of G. lamblia and E. histolytica/dispar and eggs of $E$. vermicularis and $H$. nana. The children had poor hygiene where the majority had long unclean nails. Most of them did not bring food from their homes and bought possibly contaminated unhealthy foods from poor hygienic food handlers distributed near their schools. All classes in the schools were heavily crowded with over fifty children per class. No spaces were found between desks except a narrow pathway in the middle. The children were sitting in contact with each other in continuous rows of desks. Classes with such bad conditions were supposed to be available for two periods of educational classes with no suitable time in-between for good aeration, cleaning and removal of garbage from the first period.

Concerning the village, all houses and buildings in the village had no healthy sanitation where the sewage of houses was collected in lined or unlined underground trenches. Those sewage trenches are supposed to be emptied weekly at expense of the house inhabitants so they washed their purposes in Nile water to slow down the filling of the trenches and save money and efforts required for emptying them. Furthermore, $4.04 \%$ infection rate of urinary schistosomiasis was recorded among school children of the village as the result of continuous contact with Nile water containing the intermediate host of $S$. haematobium ${ }^{[12]}$. Poverty, lack of sanitation, poor hygiene and bad environmental conditions contribute strongly to flaring up of transmission of intestinal parasites 
particularly STHs ${ }^{[1,6]}$. So governments of countries should give priority to the highly parasite-manifested areas, providing them with healthy sanitary network, safe tap water enough for drinking and washing in addition to regular removal of garbage.

Generally the Egyptian adoption of the first national deworming campaign targeting two million children aged six years is a good step towards reducing the transmission of intestinal parasites in Egypt. Strategy of selecting albendazole in mass treatment was appropriate and suitably chosen where most of prevalent parasites found in the study area as E. vermicularis were eradicated or greatly decreased as with the common intestinal protozoa as E. histolytica/dispar or G. intestinalis found among the treated children. Both albendazole and mebendazole showed high efficacies against entrobiasis and ascariasis, while the efficacy of albendazole against hookworm was relatively low, but still higher than that of mebendazole ${ }^{[25]}$, so it is recommended to use the former in areas endemic with hookworm infection.

Children of grade one, the targeted age group, were the youngest among primary age groups in the schools, chosen as those with the low hygienic knowledge and probable low immunity. However it has been recommended that a deworming campaign should include all enrolled and non-enrolled, school age children in endemic areas in order to achieve maximum reduction of transmission ${ }^{[6,7]}$. WHO sets strategies for control programs according to the parasite infection risk in communities. Accordingly the highly endemic areas recording STHs prevalence of more than $50 \%$ should be mass treated at least two or three times yearly; with four months intervals. The low risk areas with recorded prevalence ranging from 20 to less than $50 \%$ should be mass treated once a year. There is no need for mass treatment in areas of no risk (with parasite rate less than 20\%) where the positive cases should be treated and followed up on a case by case basis. Areas where schistosomiasis is endemic, are most probably also endemic with STHs, consequently albendazole should be administrated each time in mass drug administration with praziquantel for saving effort, transportation and human manpower ${ }^{[26]}$ as in case of Tamwah village which was endemic with urinary schistosomiasis ${ }^{[8]}$. So the Egyptian endemic areas with STHs, schistosomiasis and even lymphatic filariasis should be categorized and mapped according to their parasite rates for coordinating control programs and applying appropriate corresponding strategies.

\section{CONCLUSION}

E. vermicularis was the most prevalent parasite among the untreated group followed by E. histolytica/dispar, $G$. intestinalis and H. nana. Parasite rate of E. vermicularis among untreated females was more than twice that among males. The difference was statistically significant. Concerning the effect of mass treatment with albendazole, it was found that there were great significant differences between the parasite rates among the untreated and treated groups regarding E. vermicularis, E. histolytica/dispar and G. intestinalis. Meanwhile, albendazole showed no effect on parasite rate of $H$. nana. The strategy of selecting albendazole for mass treatment in such areas was appropriate and suitably chosen where most of the prevalent parasites found in that area were greatly affected. Coordination between both STH and Schistosoma control programs should be conducted simultaneously in order to save effort, time and trained manpower and transportation. Mass treatment should not be restricted to children of grade one but should include children of all grades in the primary schools (enrolled and non-enrolled) for further reduction of transmission.

\section{RECOMMENDATION}

As there are great variations in environmental conditions of the primary schools in different areas of Egypt, the areas or villages should be classified according to the intestinal parasitic rates into categories for determining the number of treatment control rounds required accordingly. Also all data about endemicity and applied control program of other diseases as schistosomiasis or lymphatic filariasis should be collected. Egypt can conduct different strategies of mass treatment programs, each strategy will be concerned with similar areas having the same diseases at the same level of risk. For example, co-endemic areas with low risk of $\mathrm{SCH}$ and STHs as Tamwah village should apply a co-ordinated control program for both STHs and SCH administrating albendazol with praziquantel annually. Preliminary parasitic classification of areas and applying the suitable strategy will organize and save wasted drugs in no or low risk areas, for use in areas of higher risk. The mass treatment inside primary schools of moderate or high parasite rate risk should include all children in all grades (enrolled and non-enrolled) and not be restricted to one grade, in order to achieve maximum reduction of transmission. Moreover at governmental level, all data and records about hot spot areas of high parasitic infection rates should be informed to authorities responsible for conducting sanitation nets and providing safe tap water adequate for daily needs, rather than just regular garbage removal and improvement of environmental conditions. Those localities should have priority in improvement and reclamations.

Acknowledgment: The author thanks Prof. Dr. Ayat AMH Aggag, Undersecretary for Endemic Diseases, Ministry of Health and Population, the leader of the first national deworming campaign; and Dr. Bahaa El Deen Farid, General Director of General Administration of Endemic Diseases Control of Giza, who provided all managerial facilities required for accomplishing the work. Thanks are also due to Dr. Mohammed Ali and all members of Tamwah Unit. 


\section{REFERENCES}

1. Dempsey TO. Soil- transmitted helminths. In Tropical Medicine Lecture Notes. 7th ed. edited by Nicke Beeching and Geoff Gill published by John Wiley \& Sons Ltd. 2014: 199-204

2. Brooker SJ, Bundy DAP. Soil transmitted helminths STHs (Geohelminths) in Manson Tropical Diseases. 2014; 23rd ed: 766-794

3. WHO. 14807th session of WHO's executive board. Geneva 2001.

4. WHO. Prevention and control of schistosomiasis and soil-transmitted helminthiasis. Report of a WHO Expert Committee: Geneva: World Health Organization 2002.

5. WHO. Soil-transmitted helminthiases: estimates of the number of children needing preventive chemotherapy and number treated, 2009. Weekly Epidemiological Record 2011; 86: 257-266.

6. WHO. Helminths control in school age children: A guide for managers of control program 2nd ed 2011.

7. WHO. Egypt's deworming campaign targets 2 million school-age children.

8. Dahesh SMA, Farid BE. Epidemiological situation of urinary schistosomiasis in Tamwah area, Giza, Egypt: assessment and control. J Egypt Soc Parasitol 2016; 46(3): 485-496

9. Cheesbrough M. District laboratory practice in tropical countries part one 2nded. 2016: 178-236

10. Altman D. Practical statistics for medical research. 1st ed. London: Chapman \& Hall. 1992.

11. Tudor G, Koch GG. Review of nonparametric methods for the analysis of crossover studies. J SAGE 1994; 3(4): $345-381$

12. Bahader SM, Ali GS, Shaalan AH, Khalil HM, Khalil NM. Effects of Enterobius vermicularis infection on intelligence quotient (I.Q) and anthropometric measurements of Egyptian rural children. J Egypt Soc Parasitol 1995; 25(1): 183-94.

13. Macedo, T, MacCarty, RL. Eosinophilicileocolitis secondary to Enterobius vermicularis: case report. Abdom Imaging 2000; 25: 530-532.

14. Arca MJ, Gates RL, Groner JI, Hammond S, Caniano DA. Clinical manifestations of appendiceal pinworms in children: an institutional experience and a review of the literature. Pediatr SurgIn t2004; 20: 372-375.

15. Jardine M, Kokai GK, Dalzell AM. Enterobius vermicularis and colitis in Children. $\mathrm{J}$ Pediatr Gastroenterol Nutr 2006; 43: 610-612.

16. Mahdy MAK, Surin J, Wan KL, Mohd-Adnan A, AlMekhlafi MS, Lim YAL. Giardia intestinalis genotypes: risk factors and correlation with clinical symptoms. Acta Trop 2009; 112: 67-70.

17. Speich B, Marti H, Ame SM, Ali SM, Bogoch II, Utzinger $\mathrm{J}$, et al. Prevalence of intestinal protozoa infection among school-aged children on Pemba Island, Tanzania, and effect of single-dose albendazole, nitazoxanide and albendazole-nitazoxanide. Parasit \& Vect 2013; 4(6): 3 .

18. Cifuentes, E, Suarez L, Espinosa M, Juarez-Figueroa L, Martinez-Palomo A. Risk of Giardia intestinalis infection in children from an artificially recharged groundwater area in Mexico City. Am J Trop Med Hyg 2004; 71: 65-70

19. Prado MS, Strina A, Barreto ML, Oliveira-AssisAM, Paz LM, Cairncross S. Risk factors for infection with Giardia duodenalis in pre-school children in the city of Salvador, Brazil. Epidemiol Infect 2003; 131: 899906.

20. Escobedo AA, Almirall P, Alfonso M, Cimerman S, Rey S, Terry SL. Treatment of intestinal protozoan infections in children. Arch Dis Child 2009; 94: 478482.

21. Rodriguez-Garcia R, Rodriguez-Guzman LM, Cruz del Castillo AH. Effectiveness and safety of mebendazole compared to nitazoxanide in the treatment of Giardia lamblia in children. Rev Gastroenterol Mex 1999; 64: 122-126.

22. Ortiz JJ, Ayoub A, Gargala G, Chegne NL, Favennec L. Randomized clinical study of nitazoxanide compared to metronidazole in the treatment of symptomatic giardiasis in children from northern Peru. Aliment Pharmacol Ther 2001;15: 1409-1415.

23. Yereli K, Balcioglu IC, Ertan P, Limoncu E, Onag A. Albendazole as an alternative therapeutic agent for childhood giardiasis in Turkey. Clin Microbiol Infect 2004; 10: 527-529.

24. Baily, G, Garcia, HH, 2014: Other cestode infections: intestinal cestodes, cysticercosis, other larval cestode infections in Manson Tropical Diseases $23^{\text {rd }}$ edition 2014: 828-829. 
25. Soukhathammavong PA, Sayasone S, Phongluxa $\mathrm{K}$, Xayaseng V, Utzinger J, Vounatsou $\mathrm{P}$, et al. Low Efficacy of single-dose albendazole and mebendazole against hookworm and effect on concomitant helminth Infection in Lao PDR. PDR. PLoSNegl Trop Dis 2012;6(1): e1417.
26. Yajima A, Gabrielli AF, Montresor A, Engels D. Moderate and high endemicity of schistosomiasis is a predictor of the endemicity of soil transmitted helminthiasis - systematic review. Trans Roy Soc Trop Med Hyg 2011;105:68-83. 